\title{
Silver nanoparticles promote osteogenic differentiation of human urine-derived stem cells at noncytotoxic concentrations
}

This article was published in the following Dove Press journal:

International Journal of Nanomedicine

20 May 2014

Number of times this article has been viewed

\author{
Hui Qin ${ }^{1, *}$ \\ Chen Zhu ${ }^{2, *}$ \\ Zhiquan An' \\ Yao Jiang' \\ Yaochao Zhao' \\ Jiaxin Wang' \\ Xin Liu' \\ Bing Hui' \\ Xianlong Zhang' \\ Yang Wang' \\ 'Department of Orthopedics, \\ Sixth People's Hospital, Shanghai \\ Jiao Tong University School of \\ Medicine, Shanghai, ${ }^{2}$ Department \\ of Orthopaedic Surgery, Provincial \\ Hospital Affiliated to Anhui Medical \\ University, HeFei, People's Republic \\ of China
}

*These authors contributed equally to this work
Correspondence: Xianlong Zhang Sixth People's Hospital, Shanghai Jiao Tong University School of Medicine, 600 Yi-Shan Road, Shanghai 200233, People's Republic of China

Tel +862164369181

Fax $+862|6470| 36 \mid$

Email zhangxianl197826@I63.com

Yang Wang

Sixth People's Hospital, Shanghai Jiao

Tong University School of Medicine,

600 Yi-Shan Road, Shanghai 200233,

People's Republic of China

Tel +862164369183

Fax +86 2I 64701363

Email wangyang197826@|63.com
Abstract: In tissue engineering, urine-derived stem cells are ideal seed cells and silver nanoparticles (AgNPs) are perfect antimicrobial agents. Due to a distinct lack of information on the effects of AgNPs on urine-derived stem cells, a study was conducted to evaluate the effects of silver ions and AgNPs upon the cytotoxicity and osteogenic differentiation of urine-derived stem cells. Initially, $\mathrm{AgNPs}$ or $\mathrm{AgNO}_{3}$ were exposed to urine-derived stem cells for 24 hours. Cytotoxicity was measured using the Cell Counting kit-8 (CCK-8) test. The effects of AgNPs or $\mathrm{AgNO}_{3}$ at the maximum safety concentration determined by the CCK-8 test on osteogenic differentiation of urine-derived stem cells were assessed by alkaline phosphatase activity, Alizarin Red S staining, and the quantitative reverse transcription polymerase chain reaction. Lastly, the effects of AgNPs or $\mathrm{AgNO}_{3}$ on "urine-derived stem cell actin cytoskeleton organization" and RhoA activity were assessed by rhodamine-phalloidin staining and Western blotting. Concentration-dependent toxicity was observed starting at an $\mathrm{AgNO}_{3}$ concentration of $2 \mu \mathrm{g} / \mathrm{mL}$ and at an AgNP concentration of $4 \mu \mathrm{g} / \mathrm{mL}$. At these concentrations, AgNPs were observed to promote osteogenic differentiation of urine-derived stem cells, induce actin polymerization and increase cytoskeletal tension, and activate RhoA; $\mathrm{AgNO}_{3}$ had no such effects. In conclusion, AgNPs can promote osteogenic differentiation of urine-derived stem cells at a suitable concentration, independently of silver ions, and are suitable for incorporation into tissue-engineered scaffolds that utilize urine-derived stem cells as seed cells.

Keywords: silver nanoparticles, osteogenic differentiation, stem cell, cytotoxicity

\section{Introduction}

Bone defects are a common and intractable clinical challenge in orthopedics; their treatment usually requires autogenous or allogenous bone grafting, which is limited by the restricted sources of autogenous bone, and immunological reactions may be caused by allogenous bone. In recent years, tissue engineering of patient-specific bone grafts has been used to treat bone defects and has become a feasible alternative to autografts and allografts. ${ }^{1}$ Advances in stem cell research show that stem cells used as seed cells have unique properties that are vital for the development of engineered tissue constructs, including high proliferation rates, self-renewal, and specialized differentiation under specific conditions. Stem cells used in tissue engineering are commonly isolated from adult bone marrow or adipose tissue. However, extraction of marrow-derived or adiposederived stem cells requires invasive procedures, and may result in additional trauma, complications, and increased health care costs, ${ }^{2}$ which restrict the use of these cells in tissue engineering. Urine-derived stem cells (USCs) are first described by Zhang et al, ${ }^{3}$ and are thought to derive from basal cells of the urothelial layer. They can be isolated 
from urine and expanded in special culture, can differentiate into cell lineages such as urothelial cells, smooth muscle cells, endothelial cells, osteocytes, chondrocytes, and adipocytes on induction with appropriate media, ${ }^{4-8}$ and have been reported recently to be ideal candidates for mesenchymal stem cells to replace marrow-derived stem cells and adipose-derived stem cells as seed cells for tissue engineering, due to their harvest from autologous urine using noninvasive, safe, low-cost, and easily reproducible methods. ${ }^{3,7}$ Currently, USCs are being investigated as cell therapies in the treatment of renal insufficiency and urinary incontinence, and for tissue engineering in bladder and urethral tissue regeneration; ${ }^{6}$ however, their use in tissue-engineering to repair bone defects is equally attractive.

The implantation of tissue-engineering scaffolds often requires invasive surgery, so infection control is a key factor in its success. ${ }^{9}$ Addition of antibiotics on the scaffolds is a common method used to prevent infection; however, their limited antibacterial spectrum and emergence of drug-resistant organisms, such as methicillin-resistant Staphylococcus aureus, restrict their use. ${ }^{10}$ Silver is a potent antimicrobial agent with broad-spectrum antimicrobial activity against Gram-negative and Gram-positive bacteria, fungi, and certain viruses, including antibiotic-resistant strains, ${ }^{11}$ less likelihood of developing resistant strains, and has been used safely in medicine for many years. ${ }^{12-14}$ For improved antibacterial activity at the nanoscale level, silver nanoparticles (AgNPs) are becoming the most useful and valuable nanomaterial in medicine. ${ }^{9}$ A number of investigators have reported the use of AgNPs in tissue engineering scaffolds, with a reduced incidence of infection and good cell compatibility. ${ }^{15,16}$

When USCs are used as seed cells and AgNPs as antimicrobial agents simultaneously in tissue engineering scaffolds to repair bone defects, the proliferation and osteogenic differentiation of USCs may be influenced by AgNPs. The premise of the above combination is that the cytotoxicity of AgNPs with USCs should be minimal and the osteogenic differentiation ability of USCs should not be compromised. Therefore, we performed this study to assess the effect of AgNPs on the viability and osteogenic differentiation of USCs. For AgNPs, inducing cytotoxicity via release of silver ions ${ }^{17}$ or AgNPs themselves, ${ }^{18}$ we must also assess the effect of silver ions on the viability and osteogenic differentiation of USCs.

The purpose of this study was to assess the effects of silver ions and AgNPs on the cytotoxicity and osteogenic differentiation of USCs. Comprehending the interactions between AgNPs and USCs is vital to being able to determine if the antibacterial ability of AgNPs negatively affects the differentiation of USCs down osteogenic pathways for tissue engineering scaffold systems.

\section{Materials and methods Silver nanoparticles}

The materials tested were $\mathrm{AgNPs}$ and silver nitrate $\left(\mathrm{AgNO}_{3}\right)$. AgNPs were purchased from Huzheng Nano Technology Co, Ltd (Shanghai, People's Republic of China) at a concentration of $2 \mathrm{mg} / \mathrm{mL}$ with average diameters of $20 \mathrm{~nm} . \mathrm{AgNO}_{3}$ was obtained from Sigma-Aldrich (Basel, Switzerland). AgNPs were purified using the method reported by Liu et $\mathrm{al}^{19}$ with slight modification. Briefly, the $20 \mathrm{~nm}$ AgNP solution was centrifuged at $21,000 \times \mathrm{g}$ for 15 minutes. The supernatant was removed, and $3 \mathrm{~mL}$ of $1 \%$ passivant $(1,2$, 3-benzitriazole) was then added to the precipitated AgNPs and removed after 20 minutes by centrifugation at 9,500× $\mathrm{g}$. Finally, the AgNPs were rinsed with acetone and absolute ethanol and dried at $45^{\circ} \mathrm{C}$ for 24 hours in a vacuum oven. After being dried, the AgNPs were suspended in deionized water using sonication for 20 minutes in an ice bath. Finally, the AgNPs were suspended in sterile deionized water as stock suspensions at a concentration of $2 \mathrm{mg} / \mathrm{mL}$ by sonication, and preserved in the dark at $4^{\circ} \mathrm{C}$. The exposure suspensions were prepared as a series of dilutions with cell culture medium by sonication for approximately 5 minutes, just before each experiment. The $\mathrm{AgNO}_{3}$ solution was prepared in the same way as mentioned above.

Transmission electron microscopy was used to characterize the morphology and size of the AgNPs. Samples were prepared by placing a drop of the AgNP solution at a concentration of $2 \mathrm{mg} / \mathrm{mL}$ in deionized water onto a formvarcoated copper grid and air drying. Samples were observed by transmission electron microscopy (H-7500; Hitachi, Tokyo, Japan).

\section{Isolation, characterization, and expansion of USCs}

Four 250-300 mL mid stream urine samples from four healthy men aged 28-34 years were collected and directly transferred to the laboratory for isolation and culture, as reported previously, ${ }^{2-5,7,8}$ with a slight modification. Briefly, urine specimens were centrifuged at $400 \times \mathrm{g}$ for 10 minutes at room temperature. The cell pellet was resuspended in $20 \mathrm{~mL}$ of phosphate-buffered saline containing $500 \mathrm{U} / \mathrm{mL}$ penicillin and $0.5 \mathrm{mg} / \mathrm{mL}$ streptomycin and gently rinsed for 5 minutes. The cell suspension was then centrifuged again at $400 \times \mathrm{g}$ for 10 minutes and the cells were plated in 12 -well plates. The USC growth medium used was composed 
of embryo fibroblast medium and keratinocyte serum-free medium (Invitrogen, Carlsbad, CA, USA) at a ratio of $1: 1$. It took 4-6 days for individual clones to emerge and 7-10 days for a single USC clone to reach confluence in the initial culture. The cells were consecutively passaged every 3-4 days. USCs (passage 3-6) were used for all experiments because they have a higher differentiation capacity. USCs at passage 3 were characterized using flow cytometry analysis as described elsewhere. ${ }^{3-5}$ Briefly, cells were trypsinized, washed in ice-cold phosphate-buffered saline containing $0.5 \%$ bovine serum albumin (wash buffer), and counted. Fluorochrome-conjugated antibodies, anti-CD34-fluorescein isothiocyanate (FITC), CD45-FITC, CD90-FITC, CD29phycoerythrin, and CD73- phycoerythrin (BD Pharmingen, Franklin Lakes, NJ, USA), were added to $5 \times 10^{5}$ cells in $50 \mu \mathrm{L}$ of phosphate-buffered saline containing $3 \%$ bovine serum albumin and incubated on ice for 30 minutes in the dark. The cells were washed again, resuspended in $50 \mu \mathrm{L}$ of wash buffer, and passed through a $70 \mu \mathrm{m}$ filter for flow analysis using a FACSCalibur machine (BD Biosciences, Franklin Lakes, NJ, USA).

The cells were then identified by adipogenic, osteogenic, and chondrogenic differentiation. For adipogenic differentiation, USCs were seeded at a density of 4,000 cells $/ \mathrm{cm}^{2}$ and cultured in growth medium to $100 \%$ confluence, then induced with Stempro ${ }^{\circledR}$ adipogenesis differentiation medium (Gibco BRL, Grand Island, NY, USA) for 2 weeks. Cells were stained with fresh Oil Red O solution (Sigma-Aldrich).

For osteogenic differentiation, USCs were seeded at a density of 3,000 cells $/ \mathrm{cm}^{2}$ and cultured in growth medium to $70 \%$ confluence, then induced with StemPro osteogenesis differentiation medium (Gibco BRL) for 3 weeks. To assess mineralization, cultures were stained with Alizarin red $\mathrm{S}$ (Sigma-Aldrich).

Chondrogenic differentiation was assessed by incubating the cells in a high-density cell pellet with StemPro chondrogenesis differentiation medium, as described by Mackay et al. ${ }^{20}$ Briefly, $3 \times 10^{5}$ cells were centrifuged at $600 \times \mathrm{g}$ for 5 minutes in a sterile $15 \mathrm{~mL}$ conical polypropylene tube and incubated overnight to form an aggregate. The culture medium was replaced with $0.5 \mathrm{~mL}$ of chondrogenic differentiation medium for a total of 28 days. Anionic sulfated proteoglycans were detected by Safranin $\mathrm{O}$ staining and toluidine blue metachromasia (Sigma-Aldrich).

\section{Cytotoxicity}

A Cell Counting Kit-8 (CCK-8; Dojindo Kagaku Co, Kumamoto, Japan) was used to investigate the cytotoxicity of silver ions and AgNPs on USCs, according to the manufacturer's protocols. The assay reagent is a tetrazolium compound (WST-x8) that is reduced by dehydrogenases in live cells into an orange-colored formazan product measured at $450 \mathrm{~nm}$. The quantity of formazan product measured at $450 \mathrm{~nm}$ is directly proportional to the number of live cells in the culture. Briefly, cells were seeded at a density of $5 \times 10^{3}$ cells per well in a 96-well plate and cultured overnight. Subsequently, fresh medium containing $\mathrm{AgNO}_{3}$ or $20 \mathrm{~nm}$ AgNPs at different concentrations $(0,0.1,0.5,1,2,4$, $8,16,32,64 \mu \mathrm{g} / \mathrm{mL}$ ) was added to replace the culture medium for 24 hours. After incubation, the culture medium containing silver was removed; $100 \mu \mathrm{L}$ of fresh medium and $10 \mu \mathrm{L}$ of CCK-8 solution were added to each well. After incubation for 4 hours, absorbance was measured using a microplate reader (ELX 800; BioTek Instruments, Inc., Winooski, VT, USA) at $450 \mathrm{~nm}$. The well with medium and CCK-8 solution but without cells was used as a blank control. The maximum safety concentration determined by CCK- 8 was used in the following experiments.

\section{Effects on osteogenic differentiation}

Alkaline phosphatase activity (ALP), Alizarin red staining, and the quantitative reverse transcription polymerase chain reaction (qRT-PCR) were used to assess for any effects of silver ions or AgNPs on osteogenic differentiation of USCs at a maximum safety concentration determined by the above cytotoxicity test $\left(\mathrm{AgNO}_{3} 2 \mu \mathrm{g} / \mathrm{mL}, 20 \mathrm{~nm} \mathrm{AgNPs} 4 \mu \mathrm{g} / \mathrm{mL}\right)$.

\section{Alkaline phosphatase activity test}

USCs were seeded into 24-well plates at a density of $2 \times 10^{4}$ cells per well. When cells were grown to $80 \%$ confluency in growth medium, they were exposed for 24 hours to $\mathrm{AgNO}_{3}$ or $20 \mathrm{~nm}$ AgNPs. After 24 hours of cultivation, the medium was removed and cells were gently rinsed three times with phosphate-buffered saline, and then differentiated down the osteogenic pathways with osteogenic differentiation medium for 21 days. ALP was measured on days $3,7,17$, and 21 . After washing three times with phosphate-buffered saline, the cells were trypsinized and scraped into $0.1 \%$ Triton $^{\mathrm{TM}} \mathrm{X}-100$ (Amresco, Solon, $\mathrm{OH}$, USA), followed by three cycles of freezing and thawing. ALP activity was determined by the biochemical colorimetric assay using an ALP kit (GeneTex Inc., Irvine, CA, USA) according to the manufacturer's instructions. ALP activity was quantified by measurement of absorbance at $405 \mathrm{~nm}$. Total protein content was determined using the bicinchoninic acid (BCA) method in aliquots of the same samples with the 
BCA protein assay kit (Pierce Biotechnology, Rockford, IL, USA), read at $562 \mathrm{~nm}$ and calculated according to a series of albumin (BSA) standards. ALP levels were normalized to total protein content at the end of the experiment.

\section{Alizarin red $\mathrm{S}$ staining}

Osteogenic induction of USCs was done using the same method as that described above for the ALP test. After 21 days, cells were rinsed with phosphate-buffered saline and fixed with $4 \%$ formaldehyde solution, then stained with Alizarin red S. The unbound dyes were completely eliminated by thorough washing with phosphate-buffered saline before images were taken. To quantify the extent of matrix mineralization, Alizarin red S-stained cultures were incubated in cetylpyridinium chloride to dissolve and release calcium-bound Alizarin red S into solution, as reported previously. ${ }^{21}$ Absorbance of the released Alizarin red $\mathrm{S}$ was measured at $562 \mathrm{~nm}$. Values were normalized against protein concentration. The assay was performed in triplicate.

\section{qRT-PCR}

USCs were seeded into six-well plates at a density of $1 \times 10^{5}$ cells per well and differentiated down the osteogenic pathways as described above. Total RNA was isolated from USC using Trizol reagent (Invitrogen) on days 7, 14, and 21. The RNA obtained was reverse transcribed into complementary DNA using the PrimeScript RT reagent kit (Takara, Shiga, Japan) and the qRT-PCR analysis was performed on a C1000 instrument (Bio-Rad, Hercules, CA, USA) using SYBR Premix Ex Taq II (Takara). The primers for the target genes are listed in Table 1. Target gene expression levels were normalized to that of the housekeeping gene, glyceraldehyde-3-phosphate dehydrogenase.

\section{Effects on organization of the actin cytoskeleton}

The cytoskeleton of USCs exposed to silver ions at $2 \mu \mathrm{g} / \mathrm{mL}$ or AgNPs at $4 \mu \mathrm{g} / \mathrm{mL}$ was observed by laser scanning confocal microscopy. A $200 \mu \mathrm{L}$ cell suspension with a cell density of
$2 \times 10^{4}$ cells $/ \mathrm{mL}$ was seeded onto each sterilized $2 \mathrm{~cm} \times 2 \mathrm{~cm}$ coverslip in a six-well plate and incubated for 4 hours to allow cell attachment. Next, $2 \mathrm{~mL}$ of fresh medium was added to each well for incubation overnight. Fresh medium containing $\mathrm{AgNO}_{3}$ or AgNPs at the above concentration was then added to replace the culture medium. After incubating for 24 hours, the seeded cells were fixed in 4\% formaldehyde solution and permeabilized with $0.5 \%(\mathrm{v} / \mathrm{v})$ Triton X-100, then stained with rhodamine phalloidin (Invitrogen) and 4',6-diamidino2-phenylindole dihydrochloride (DAPI, Calbiochem ${ }^{\circledR}$; Merck Millipore, Billerica, MA, USA). The cytoskeletal actin and cell nuclei were examined by laser scanning confocal microscopy (LSM 510 Meta; Zeiss, Oberkochen, Germany).

\section{RhoA activity assay}

USCs were seeded into T- 25 flasks at a density of $1 \times 10^{5}$ cells per flask. When the cells were grown to $80 \%$ confluency in growth medium, they were exposed to $\mathrm{AgNO}_{3}$ or AgNPs at the above concentration for 24 hours, and then lysed in solution as described by McBeath et al. ${ }^{22}$ The lysates were centrifuged at $3,000 \times \mathrm{g}$ for 3 minutes at $4{ }^{\circ} \mathrm{C}$. the supernatants were incubated with rhotekin-conjugated agarose beads (Upstate, Billerica, MA, USA) for 45 minutes at $4{ }^{\circ} \mathrm{C}$, centrifuged for 3 minutes at 3,000×g, washed in wash buffer, then suspended in sodium dodecyl sulfate polyacrylamide gel electrophoresis buffer $(1.5 \times / 1.5 \% \beta$-mercaptoethanol). RhoA was detected by Western blotting using a monoclonal antibody to RhoA (Santa Cruz Biotechnology, Santa Cruz, CA, USA).

\section{Statistical analysis}

Experiments were performed in triplicate and the data are shown as the mean \pm standard deviation. All statistical analyses were performed using Statistical Package for the Social Sciences version 18 software (SPSS, Chicago, IL, USA). To determine the statistical significance of observed differences between the study groups, the unpaired Student's $t$-test was applied when data were normally distributed and the Mann-Whitney $U$ test was used when the data were

Table I Primers used for quantitative reverse transcription polymerase chain reaction

\begin{tabular}{lll}
\hline Gene & Forward primer sequence (5-3) & Reverse primer sequence (5-3) \\
\hline RUNX2 & CCAACCCACGAATGCACTATC & TAGTGAGTGGTGGCGGACATAC \\
OPN & GCCGAGGTGATAGTGTGGTT & TGAGGTGATGTCCTCGTCTG \\
OCN & CGCTACCTGTATCAATGGCTGG & CTCCTGAAAGCCGATGTGGTCA \\
BMP2 & GAGAAGGAGGAGGCAAAGAAA & AGCAGCAACGCTAGAAGACAG \\
COLIAI & GCCCAGAAGAACTGGTACATCAG & CGCATACTCGAACTGGAATC \\
ALP & AACGTGGCCAAGAACATCATCA & TGTCCATCTCCAGCCGTGTC \\
GAPDH & ATCCCATCACCATCTTCC & GAGTCCTTCCACGATACCA \\
\hline
\end{tabular}


independently distributed. A $P$-value less than 0.05 was considered to be statistically significant.

\section{Results \\ Characterization of AgNPs}

The morphology of the AgNPs as observed by transmission electron microscopy is shown in Figure 1A. The mean AgNP particle size was 19.4 $\pm 5.2 \mathrm{~nm}$ (Figure 1B).

\section{Characterization of USCs}

Immunophenotyping for surface antigens of USC was done by flow cytometry (see Figure 2A), which revealed that USCs from passage 3 stained positive for the mesenchymal stem cell markers CD29, CD73, and CD90, but negative for the hematopoietic lineage markers CD34 and CD45. The results of trilineage differentiation shown in Figure 2B indicate that USCs differentiated into osteoblasts, adipoblasts, and chondroblasts in appropriate differentiation media. The results for stem cell marker expression and multidifferentiation capacity indicate that these USCs are a type of mesenchymal stem cell.

\section{Cytotoxicity}

As a preliminary experiment, we assessed the cytotoxicity of $\mathrm{AgNO}_{3}$ or $20 \mathrm{~nm} \mathrm{AgNPs}$ by measuring cell viability. Viability of USCs after 24 hours of exposure to the test materials is shown in Figure 3. No significant cytotoxicity was observed on exposure to up to $2 \mu \mathrm{g} / \mathrm{mL}$ of $\mathrm{AgNO}_{3}$ or $4 \mu \mathrm{g} / \mathrm{mL}$ of $20 \mathrm{~nm}$ AgNPs. These results suggest that low doses of $\mathrm{AgNO}_{3}$ or $20 \mathrm{~nm} \mathrm{AgNPs}$ do not decrease cell viability, but that exposure to silver ions and AgNPs causes significant cytotoxicity at higher doses $\left(\mathrm{AgNO}_{3}>2.0 \mu \mathrm{g} / \mathrm{mL}, 20 \mathrm{~nm}\right.$ AgNPs $>4.0 \mu \mathrm{g} / \mathrm{mL}$ ). In this study, we chose $2.0 \mu \mathrm{g} / \mathrm{mL}$ and $4.0 \mu \mathrm{g} / \mathrm{mL}$ as the respective exposure doses for $\mathrm{AgNO}_{3}$
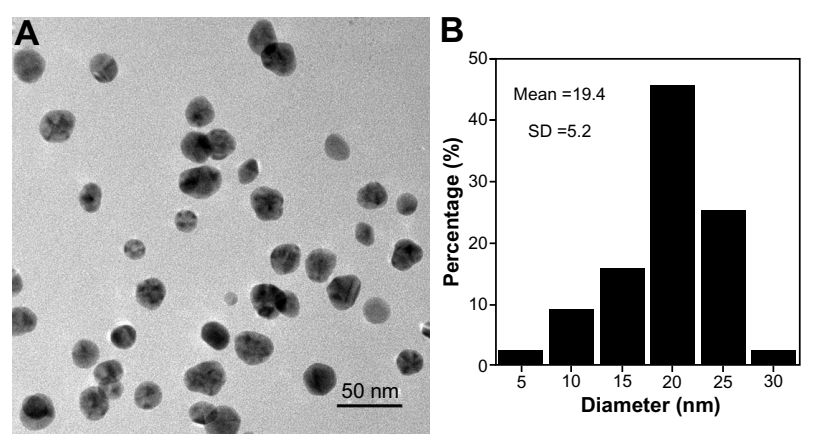

Figure I Morphology and size of the silver nanoparticles. (A) Transmission electron microscopic image of silver nanoparticles dispersed on a transmission electron microscopy copper grid. (B) A histogram showing size distribution of the silver nanoparticles.

Abbreviation: SD, standard deviation. and $20 \mathrm{~nm}$ AgNPs in the following experiments, at which significant cytotoxicity was not observed.

\section{Effects on differentiation ALP tests}

The assessed ALP activity after 3, 7, 14, and 21 days of culture was normalized by the corresponding protein content of each sample. As shown in Figure 4, there were no significant differences in ALP activity between control and $\mathrm{AgNO}_{3}$ exposed cells at any time point. However, ALP activity in AgNP-exposed cells was markedly higher. Significant differences were found between the treatment groups on days 7,14 , and 21 .

\section{Alizarin red S staining}

Extracellular matrix mineralization in the cells as evaluated by Alizarin red S staining is shown in Figure 5. There were more mineralized nodules among AgNP-exposed cells than in controls and $\mathrm{AgNO}_{3}$-exposed cells (Figure 5A). After spectromorphometric quantification and protein normalization, USCs exposed to AgNPs showed an approximately 2-fold increase in extracellular matrix mineralization as compared with controls and cells exposed to $\mathrm{AgNO}_{3}$, but no obvious differences were observed between the treatment groups (Figure 5B).

\section{qRT-PCR}

The main differentiation markers, ie, runt-related transcription factor 2 (RUNX 2), ALP, collagen I (COL1A1), osteocalcin $(O C N)$, osteopontin $(O P N)$, and bone morphogenic protein-2 (BMP-2),-were analyzed on days 7,14 , and 21 , as shown in Figure 6. Expression of all these gene markers was found in control cells on day 7, with peak $A L P$ and COL1A1 being evident on day 14, and $O P N, O C N, R U N X 2$, and $B M P-2$ on day 21. There were no obvious differences in gene expression between at the three time points. However, compared with control cells and $\mathrm{AgNO}_{3}$-exposed cells, expression of the above genes in AgNP-exposed cells was significantly increased. Compared with control cells, expression of RUNX 2, ALP, BMP-2, COL1A1, OCN, and $O P N$ in AgNP-exposed cells on days 7, 14, and 21 was increased by: 2.4-fold, 2.0 -fold, and 2.3-fold; 5.9-fold, 9.0-fold, and 3.5-fold; 6.6-fold, 11.0-fold, and 2.0-fold; 2.1-fold, 2.0-fold, and 1.8-fold; 4,0-fold, 7.0-fold, and 2.0-fold; and 4.2-fold, 5.2-fold and 2.4-fold, respectively.

\section{Actin cytoskeleton organization}

Actin stress fiber staining was normal in control USCs (Figure 7A). Compared with the controls, cells treated with $20 \mathrm{~nm}$ AgNPs showed prominent, well organized, actin stress 

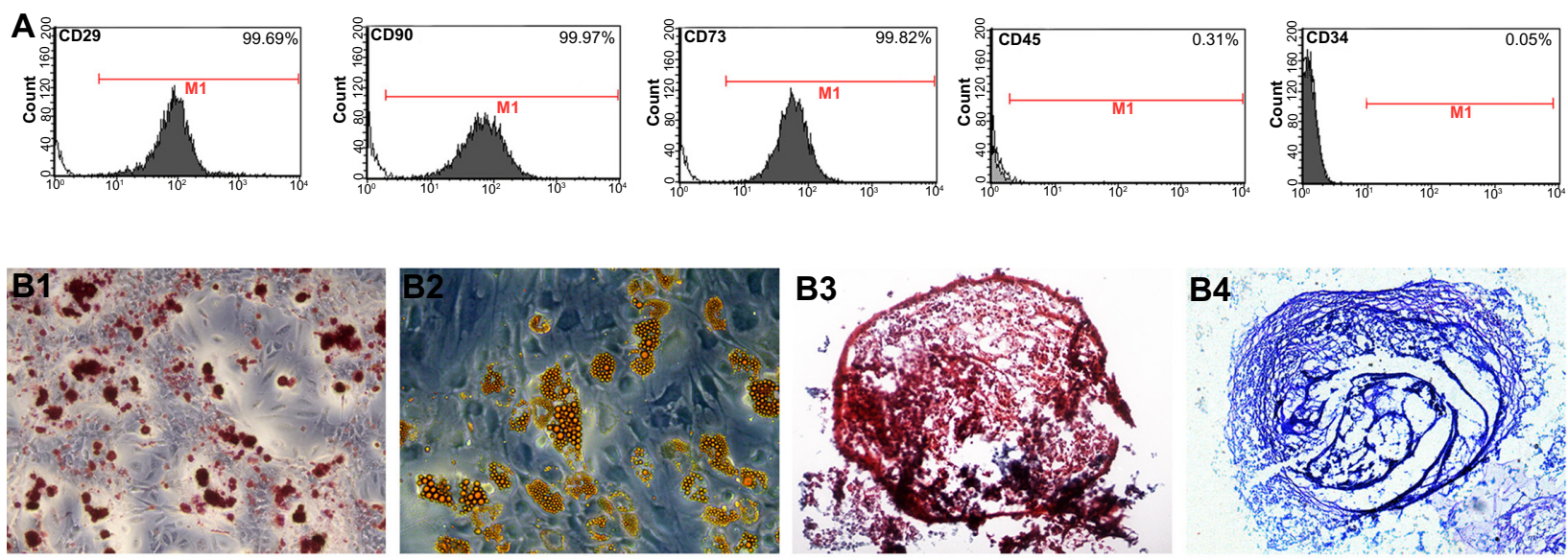

Figure 2 Characterization of urine-derived stem cells. (A) Surface marker expression in urine-derived stem cells assessed by flow cytometry. Urine-derived stem cells at passage 3 were strongly positive for mesenchymal stem cell markers, such as CD29, CD73, CD90, and negative for hematopoietic stem cell markers such as CD34 and CD45. (B) Trilineage differentiation in vitro. (B I) Osteogenic differentiation on day 21: Alizarin red S staining for calcium deposition. (B2) Adipogenic differentiation on day 14: Oil Red O staining of lipid droplets. (B3 and B4) Chondrogenic differentiation on day 2I: (B3) Safranin O staining of pellet culture and (B4) toluidine blue staining of pellet culture.

Note: Manufacturer details for Alizarin red S, Oil Red O, Safranin O and toluidine blue is Sigma-Aldrich, Basel, Switzerland.

fibers, suggesting that AgNPs of this size can enhance actin polymerization of USCs. However, there were no significant differences in this regard between cells treated with $\mathrm{AgNO}_{3}$ and control cells.

\section{Activation of RhoA}

As shown in Figure 7B, there was no significant change in total RhoA protein expression between the control, $\mathrm{AgNO}_{3}-$ exposed, and AgNP-exposed cells. In contrast, we detected an obvious induction in the activated, GTP-bound form of RhoA in AgNP-treated cells, which were less obvious in control and $\mathrm{AgNO}_{3}$-treated cells. After densitometric quantification (Figure 7C), USCs exposed to AgNPs showed an approximately 2-fold increase in GTP-RhoA levels when compared with controls and cells exposed to $\mathrm{AgNO}_{3}$, but no obvious differences were observed between the treatment groups.

\section{Discussion}

The premise of using USCs as seed cells and AgNPs as antimicrobial agents simultaneously in tissue engineering scaffolds for repairing bone defects is that the negative impact of AgNPs on the vitality and capacity of USCs for osteogenic differentiation should be minimal. Inducing cytotoxicity via release of silver ions ${ }^{17}$ or AgNPs themselves, ${ }^{18}$ this study validated the use of AgNPs incorporated into a tissue-engineered scaffold by assessing their cytotoxicity and their effect on osteogenic differentiation of USCs following exposure to either $\mathrm{AgNO}_{3}$ as the silver ion source or $20 \mathrm{~nm}$ AgNPs.

From a cytotoxicity standpoint, concentration-dependent toxicity was observed for USCs starting at an $\mathrm{AgNO}_{3}$ concentration of $2 \mu \mathrm{g} / \mathrm{mL}$ or at an AgNP concentration of $4 \mu \mathrm{g} / \mathrm{mL}$. Thus, we attained the maximum safety concentration of
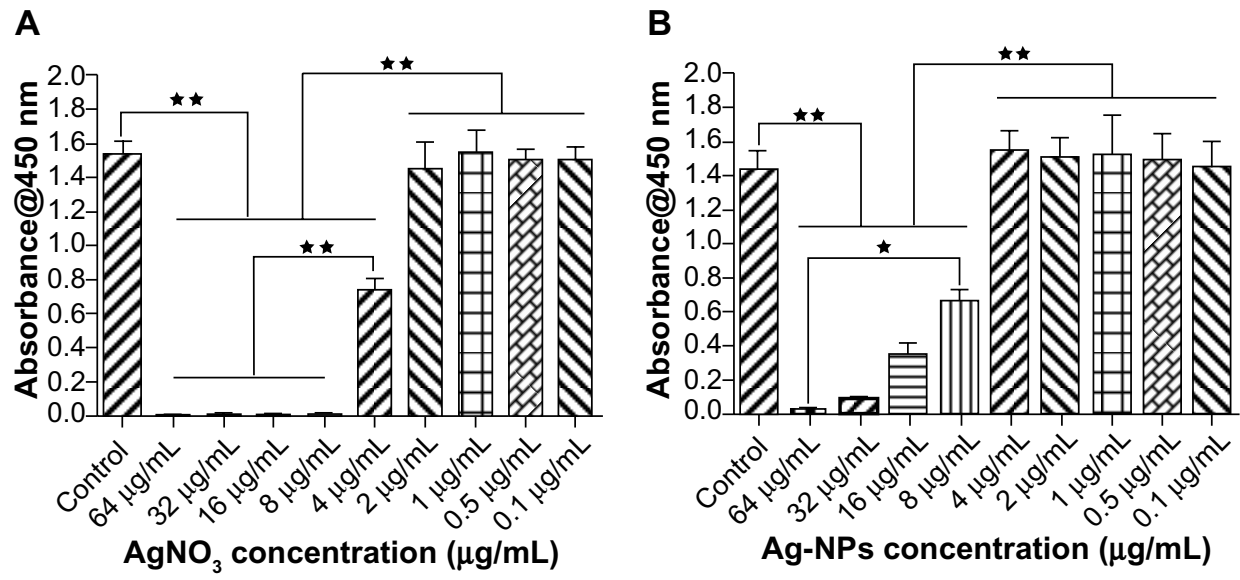

Figure 3 Cytotoxic effects of different concentrations of $\mathrm{AgNO}_{3}$ or silver nanoparticles on urine-derived stem cells. Cell Counting Kit-8 (CCK-8; Dojindo Laboratories, Kumamoto, Japan) viability of urine-derived stem cells treated with (A) $\mathrm{AgNO}_{3}$ or (B) silver nanoparticles for 24 hours. Mean ( \pm standard deviation) values are shown. $* P<0.05 ; * * P<0.01$. 


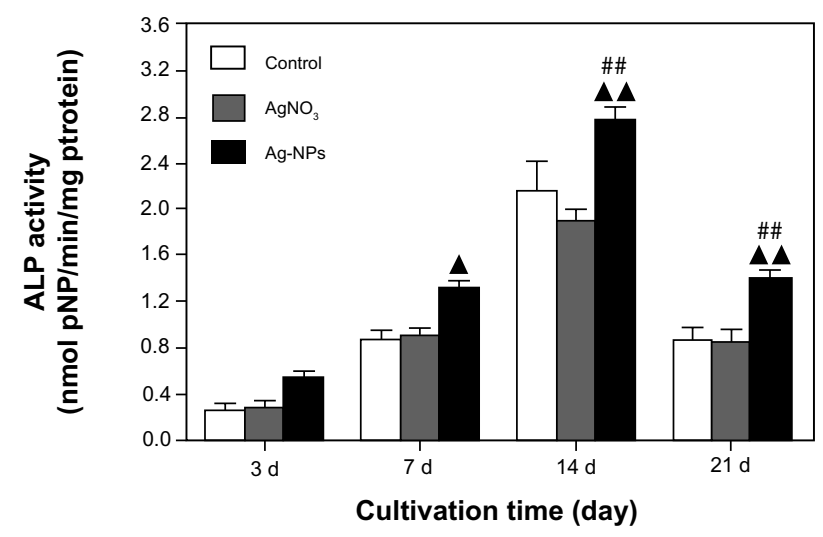

Figure 4 ALP assay. ALP activity in the USCs was measured using the p-nitrophenyl phosphate assay and normalized according to protein content. ALP activity in the AgNP-treated USCs was markedly higher than that of the control and $\mathrm{AgNO}_{3}$ treated USCs. ${ }^{\wedge} P<0.05, \triangle \Delta P<0.0$ I versus control USCs; ${ }^{\# P} P<0.01$ versus $\mathrm{AgNO}_{3}$ treated USCs.

Abbreviations: AgNPs, silver nanoparticles; ALP, alkaline phosphatase; USCs, urine-derived stem cells.

AgNPs $(4.0 \mu \mathrm{g} / \mathrm{mL})$ and $\mathrm{AgNO}_{3}(2.0 \mu \mathrm{g} / \mathrm{mL})$ for USCs, which are higher than the minimal inhibitory concentrations for AgNPs $(0.7 \mathrm{ng} / \mathrm{mL}$ for Saccharomyces cerevisiae, $0.35 \mathrm{ng} / \mathrm{mL}$ for Escherichia coli, and $3.5 \mathrm{ng} / \mathrm{mL}$ for S. aureus). ${ }^{23}$ Because AgNPs and silver ions have an antibacterial role, we chose the maximum safety concentrations that could obtain the best antibacterial effect to assess their impact on cell osteogenic differentiation.

Interestingly, the results of the ALP test and Alizarin Red S staining show that exposure to AgNPs can promote rather than compromise osteogenetic differentiation of USCs, but that exposure to $\mathrm{AgNO}_{3}$ cannot influence the intended osteogenic differentiation of USCs. Similar findings have been reported by Mahmood et al, who found that several nanomaterials containing AgNPs can induce enhanced mineralization in MC3T3-E1 bone cells, and that AgNPs do this via expression of specific genes associated with bone formation. ${ }^{24}$

Expression of osteogenesis-related genes, including $A L P$, $O P N, O C N, B M P-2, C O L 1 A 1$, and $R U N X 2$, in osteoinduced USCs were detected at days 7, 14, and 21 by qRT-PCR. There were some differences in osteogenesis-related gene expression patterns between USC and marrow-derived stem cells or adipose-derived stem cells induced in osteogenic differentiation medium. Malaval et al reported that $A L P$ expression were highest in osteoinduced marrow-derived stem cells at day $8,{ }^{25}$ while peak $A L P$ expression appeared at day 14 in osteoinduced USCs. No $B M P-2$ expression in osteoinduced adipose-derived stem cell was detected by Zuk et al, ${ }^{26}$ but was found at day 7 in osteoinduced USCs, and increased with time. Such differences can be explained by the different sources of stem cells, and, to some extent, reflect some characteristics of USCs. After exposure to $\mathrm{AgNO}_{3}$, no significant changes were found in expression of these genes in osteoinduced USCs. However, after exposure to AgNPs, expression of these genes was upregulated significantly. These results demonstrate that AgNPs generally upregulate osteogenesis-related gene expression, and correspond well with the results of ALP testing and Alizarin Red S staining, indicating that AgNPs stimulate osteogenic differentiation of USC via upregulation of the gene expression responsible for osteogenic differentiation.

How do AgNPs promote osteogenetic differentiation of USCs? Huang et al described how mesoporous silica nanoparticles can activate RhoA and lead to polymerization of actin, then induce osteogenic signals in human marrow-derived stem cells. ${ }^{27}$ Upregulated activation of RhoA levels and increased cytoskeletal tension have been shown by many researchers to lead stem cells into osteogenic differentiation. ${ }^{22,28,29}$
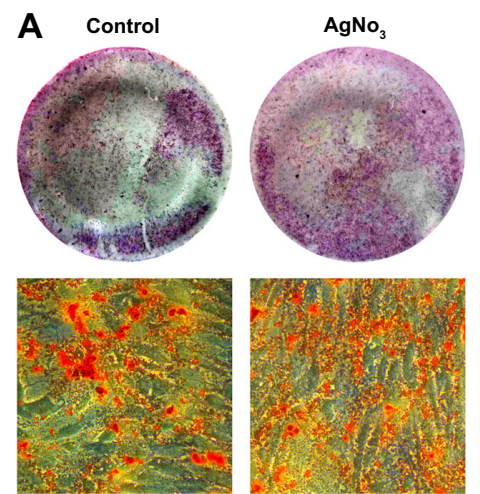
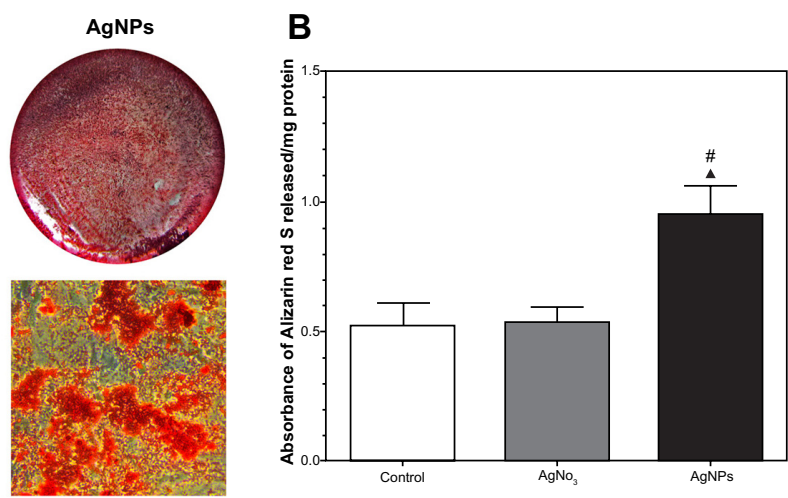

Figure 5 Extracellular matrix mineralization of USCs stained by Alizarin red S (Sigma-Aldrich, Basel, Switzerland). (A) Alizarin red S staining showed more mineralized nodules in the AgNP-treated USCs 21 days after osteogenic induction. (B) Quantitative analysis normalized according to protein content showed an approximately two-fold increase in extracellular matrix mineralization in the AgNP-treated USCs compared with the control and $\mathrm{AgNO}_{3}$-treated USCs. ${ }^{\wedge} P<0.05$ versus control USCs; ${ }^{P}<0.05$ versus $\mathrm{AgNO}_{3}$-treated USCs.

Abbreviations: AgNPs, silver nanoparticles; USCs, urine-derived stem cells. 

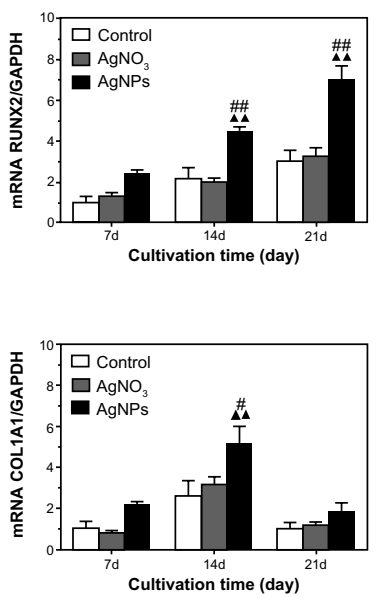
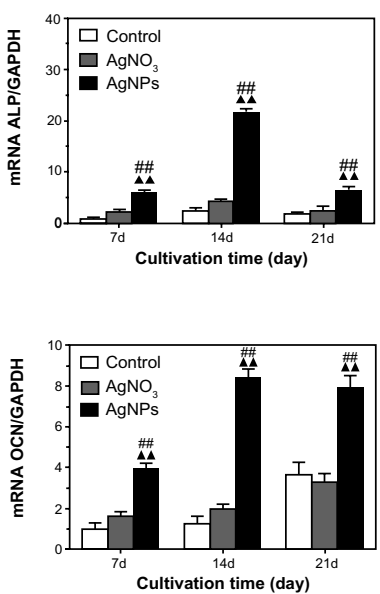
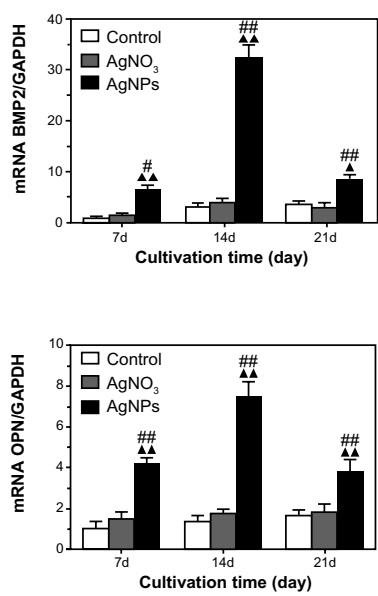

Figure 6 RUNX2, ALP, BMP-2, Col-IAI, OCN, and OPN gene transcription determined by real-time quantitative polymerase chain reaction analysis. Target gene expression levels were normalized to that of the housekeeping gene, GAPDH. The mRNA levels shown are relative to the mRNA level of the control USCs. $\triangle P<0.05$ and $\triangle \mathbf{\Delta} P<0.0$ I versus control USCs; ${ }^{\#} P<0.05$ and ${ }^{\# P}<0.01$ versus $\mathrm{AgNO}_{3}$-treated USCs.

Abbreviations: AgNPs, silver nanoparticles; GAPDH, glyceraldehyde-3-phosphate dehydrogenase; USCs, urine-derived stem cells.

McBeath et al reported that inactivating RhoA caused adipogenesis while activating RhoA promoted osteogenesis of marrow-derived stem cells, and noted that active RhoA induced osteogenesis by activating Rho kinase and then increasing cytoskeletal tension. ${ }^{22}$ Arnsdorf et al also reported that activation of Rho can result in enhanced actin cytoskel- etal tension and believed that activation of RhoA and the resultant isometric tension within the actin cytoskeleton may be necessary for osteogenic differentiation of stem cells. ${ }^{29}$ Therefore, we assumed that promotion of osteogenic differentiation in USCs by AgNPs may be via activating RhoA and increasing cytoskeletal tension.

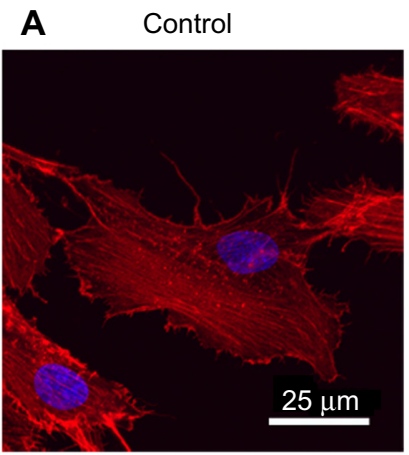

B

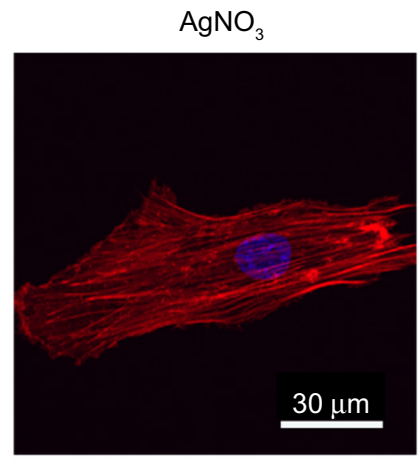

C
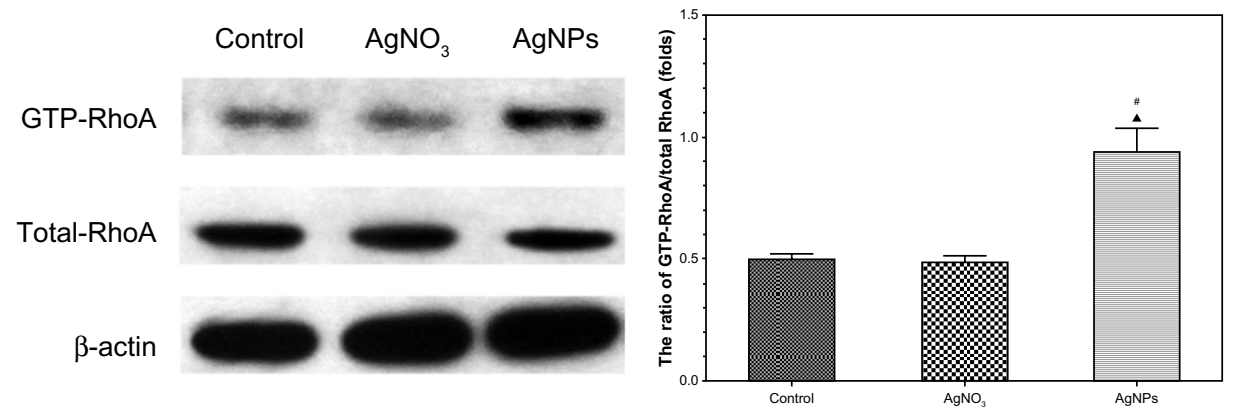

Figure 7 Actin stress fiber staining and RhoA activity assay. USCs were treated with $\mathrm{AgNO}_{3} 2.0 \mu \mathrm{g} / \mathrm{mL}$ or AgNPs $4.0 \mu \mathrm{g} / \mathrm{mL}$ for 24 hours. (A) Filamentous actin (red) was stained with rhodamine-phalloidin and the nucleus (blue) was visualized by DAPI stain. Staining of filamentous actin in the AgNP-treated USCs was stronger than that of the control and $\mathrm{AgNO}_{3}$-treated USCs. (B) Western blot of activated (GTP-bound) RhoA and total RhoA levels in USCs. $\beta$-actin was used as a control for equal loading. Western blotting confirmed the obvious expression of GTP-bound RhoA in the AgNP-treated USCs and less expression in the control and $\mathrm{AgNO}_{3}$-treated USCs. (C) Quantification was performed using scanning densitometry. Levels of GTP-bound RhoA were normalized to levels of total RhoA. Quantitative analysis revealed an increase of about two-fold in GTP-bound RhoA in the AgNP-treated USCs compared with the control and $\mathrm{AgNO}_{3}$-treated USCs. $\mathbf{\Delta P}<0.05$ versus control USCs, $\# P<0.05$ versus $\mathrm{AgNO}_{3}$-treated USCs. Abbreviations: AgNPs, silver nanoparticles; USCs, urine-derived stem cells; DAPI, 4',6-diamidino 2-phenylindole dihydrochloride. 
To determine the effects of AgNPs on actin organization, USCs were fixed and stained with rhodamine-phalloidin to label actin stress fibers. As shown in Figures 4 and 5, cells treated with AgNPs showed prominent well organized actin stress fibers compared with controls and cells treated with $\mathrm{AgNO}_{3}$, suggesting that AgNPs can enhance actin polymerization of USCs. Further, we examined the activation state of RhoA in USCs after exposure to AgNPs. Western blot analysis showed induction of increased RhoA activity along with actin polymerization in response to treatment with AgNPs (Figure 7B and C). Such a change was not observed in cells treated with $\mathrm{AgNO}_{3}$. These results confirmed our assumption that AgNPs can activate RhoA, induce actin polymerization, and increase cytoskeletal tension, thereby leading USCs into osteogenic differentiation.

How do AgNPs activate RhoA in USCs? Khatiwala et al reported that changes in substrate compliance are transduced by integrins that cluster in the plane of the plasma membrane, in turn stimulating downstream protein tyrosine kinases to catalyze the activation of RhoA. ${ }^{28}$ After USCs are exposed to AgNPs, AgNPs can adhere to the surface of the plate and come into contact with the cell membrane, which can be regarded in part as changes in substrate compliance, and interact with specific integrins of USCs and then activate RhoA. Work of mechanism research is in progress.

To our knowledge, this is the report showing that AgNPs can advance osteogenetic differentiation of USCs at noncytotoxic concentrations after exposure for 24 hours. These findings are important for tissue engineering, and make it possible that AgNPs at an appropriate concentration can coexist with USCs in the tissue engineering scaffolds to repair bone defect and inhibit infection. Further work is being done to verify this effect of AgNPs on USCs in the long term and in vivo.

In this work, we only studied one type of AgNP, but the characteristics of AgNPs vary widely according to their size, ${ }^{19}$ shape,${ }^{30}$ and surface coating material. ${ }^{31}$ For example, Samberg et al reported that two sizes of spherical AgNPs (10 nm and $20 \mathrm{~nm}$ ) had mildly toxic effects on human adipose-derived stem cells at a concentration of 10 $\mu \mathrm{g} / \mathrm{m} ;{ }^{9}$ however, at this concentration, Hackenberg et al reported that spherical and fractionally elongated AgNPs with a mean diameter of $46 \pm 21 \mathrm{~nm}$ showed significant cytotoxicity and significantly decreased the viability of human adipose-derived stem cells. ${ }^{32}$ More research should be done to assess the effects of different AgNP on USCs before USCs and concrete AgNPs can be used in tissueengineered scaffolds.

\section{Conclusion}

This study shows minimal dose-dependent toxicity of AgNPs and $\mathrm{AgNO}_{3}$ on USCs at respective concentrations of $4 \mu \mathrm{g} / \mathrm{mL}$ and $2 \mu \mathrm{g} / \mathrm{mL}$. At these concentrations, AgNPs induced actin polymerization, improved cytoskeletal tension, and activated RhoA, which promoted osteogenic differentiation of USCs. Because $\mathrm{AgNO}_{3}$ has no such effect, we believe that promotion of osteogenetic differentiation in USCs by AgNPs results from the AgNPs themselves, rather than the silver ions they release. From these results, we can conclude that AgNPs are suitable for incorporation into tissue-engineered scaffolds that utilize USCs to repair bone defects.

\section{Acknowledgment}

This study was funded by a grant from the National Natural Science Foundation of China (81171688).

\section{Disclosure}

The authors report no conflicts of interest in this work.

\section{References}

1. Vergroesen PP, Kroeze RJ, Helder MN, Smit TH. The use of poly(Llactide-co-caprolactone) as a scaffold for adipose stem cells in bone tissue engineering: application in a spinal fusion model. Macromol Biosci. 2011;11(6):722-730.

2. Liu G, Pareta RA, Wu R, et al. Skeletal myogenic differentiation of urine-derived stem cells and angiogenesis using microbeads loaded with growth factors. Biomaterials. 2013;34(4):1311-1326.

3. Zhang Y, McNeill E, Tian H, et al. Urine derived cells are a potential source for urological tissue reconstruction. J Urol. 2008;180(5): 2226-2233.

4. Bharadwaj S, Liu G, Shi Y, et al. Characterization of urine-derived stem cells obtained from upper urinary tract for use in cell-based urological tissue engineering. Tissue Eng Part A. 2011;17(15-16):2123-2132.

5. Lang R, Liu G, Shi Y, et al. Self-renewal and differentiation capacity of urine-derived stem cells after urine preservation for 24 hours. PLoS One. 2013;8(1):e53980.

6. Bharadwaj S, Liu G, Shi Y, et al. Multi-potential differentiation of human urine-derived stem cells: potential for therapeutic applications in urology. Stem Cells. 2013;31(9):1840-1856.

7. Wu S, Wang Z, Bharadwaj S, Hodges SJ, Atala A, Zhang Y. Implantation of autologous urine derived stem cells expressing vascular endothelial growth factor for potential use in genitourinary reconstruction. J Urol. 2011;186(2):640-647.

8. Wu S, Liu Y, Bharadwaj S, Atala A, Zhang Y. Human urine-derived stem cells seeded in a modified $3 \mathrm{D}$ porous small intestinal submucosa scaffold for urethral tissue engineering. Biomaterials. 2011;32(5):1317-1326.

9. Samberg ME, Loboa EG, Oldenburg SJ, Monteiro-Riviere NA. Silver nanoparticles do not influence stem cell differentiation but cause minimal toxicity. Nanomedicine (Lond). 2012;7(8):1197-1209.

10. Ovington LG. The truth about silver. Ostomy Wound Manage. 2004;50(Suppl 9A):1S-10S.

11. Rai M, Yadav A, Gade A. Silver nanoparticles as a new generation of antimicrobials. Biotechnol Adv. 2009;27(1):76-83. 
12. Lansdown A. Silver I: its antibacterial properties and mechanism of action. J Wound Care. 2002;11(4):125-130.

13. Klasen HJ. Historical review of the use of silver in the treatment of burns. I. Early uses. Burns. 2000;26(2):117-130.

14. Castellano JJ, Shafii SM, Ko F, et al. Comparative evaluation of silvercontaining antimicrobial dressings and drugs. Int Wound J. 2007;4(2): 114-122.

15. Zheng Z, Yin W, Zara JN, et al. The use of BMP-2 coupled-nanosilverPLGA composite grafts to induce bone repair in grossly infected segmental defects. Biomaterials. 2010;31(35):9293-9300.

16. Liu Y, Zheng Z, Zara JN, et al. The antimicrobial and osteoinductive properties of silver nanoparticle/poly (DL-lactic-co-glycolic acid)coated stainless steel. Biomaterials. 2012;33(34):8745-8756.

17. Park EJ, Yi J, Kim Y, Choi K, Park K. Silver nanoparticles induce cytotoxicity by a Trojan-horse type mechanism. Toxicol In Vitro. 2010;24(3):872-878.

18. Kim S, Choi JE, Choi J, et al. Oxidative stress-dependent toxicity of silver nanoparticles in human hepatoma cells. Toxicol In Vitro. 2009;23(6):1076-1084.

19. Liu $\mathrm{W}, \mathrm{Wu} \mathrm{Y}$, Wang $\mathrm{C}$, et al. Impact of silver nanoparticles on human cells: effect of particle size. Nanotoxicology. 2010;4(3):319-330.

20. Mackay AM, Beck SC, Murphy JM, Barry FP, Chichester CO, Pittenger MF. Chondrogenic differentiation of cultured human mesenchymal stem cells from marrow. Tissue Eng. 1998;4(4):415-428.

21. Ratisoontorn C, Seto ML, Broughton KM, Cunningham ML. In vitro differentiation profile of osteoblasts derived from patients with SaethreChotzen syndrome. Bone. 2005;36(4):627-634.

22. McBeath R, Pirone DM, Nelson CM, Bhadriraju K, Chen CS. Cell shape, cytoskeletal tension, and RhoA regulate stem cell lineage commitment. Dev Cell. 2004;6(4):483-495.

23. Kim JS, Kuk E, Yu KN, et al. Antimicrobial effects of silver nanoparticles. Nanomedicine. 2007;3(1):95-101.
24. Mahmood M, Li Z, Casciano D, et al. Nanostructural materials increase mineralization in bone cells and affect gene expression through miRNA regulation. J Cell Mol Med. 2011;15(11):2297-2306.

25. Malaval L, Modrowski D, Gupta AK, Aubin JE. Cellular expression of bone-related proteins during in vitro osteogenesis in rat bone marrow stromal cell cultures. J Cell Physiol. 1994;158(3):555-572.

26. Zuk PA, Zhu M, Ashjian P, et al. Human adipose tissue is a source of multipotent stem cells. Mol Biol Cell. 2002;13(12):4279-4295.

27. Huang S, Chen CS, Ingber DE. Control of cyclin D1, p27(Kip1), and cell cycle progression in human capillary endothelial cells by cell shape and cytoskeletal tension. Mol Biol Cell. 1998;9(11): 3179-3193.

28. Khatiwala CB, Kim PD, Peyton SR, Putnam AJ. ECM compliance regulates osteogenesis by influencing MAPK signaling downstream of RhoA and ROCK. J Bone Miner Res. 2009;24(5):886-898.

29. Arnsdorf EJ, Tummala P, Kwon RY, Jacobs CR. Mechanically induced osteogenic differentiation - the role of RhoA, ROCKII and cytoskeletal dynamics. J Cell Sci. 2009;122 Pt 4:546-553.

30. Pal S, Tak YK, Song JM. Does the antibacterial activity of silver nanoparticles depend on the shape of the nanoparticle? A study of the Gram-negative bacterium Escherichia coli. Appl Environ Microbiol. 2007;73(6):1712-1720.

31. Sur I, Cam D, Kahraman M, Baysal A, Culha M. Interaction of multi-functional silver nanoparticles with living cells. Nanotechnology. 2010;21(17):175104.

32. Hackenberg S, Scherzed A, Kessler M, et al. Silver nanoparticles: evaluation of DNA damage, toxicity and functional impairment in human mesenchymal stem cells. Toxicol Lett. 2011;201(1): $27-33$.
International Journal of Nanomedicine

\section{Publish your work in this journal}

The International Journal of Nanomedicine is an international, peerreviewed journal focusing on the application of nanotechnology in diagnostics, therapeutics, and drug delivery systems throughout the biomedical field. This journal is indexed on PubMed Central, MedLine, CAS, SciSearch ${ }^{\circledR}$, Current Contents ${ }^{\circledR} /$ Clinical Medicine,

\section{Dovepress}

Journal Citation Reports/Science Edition, EMBase, Scopus and the Elsevier Bibliographic databases. The manuscript management system is completely online and includes a very quick and fair peer-review system, which is all easy to use. Visit http://www.dovepress.com/ testimonials.php to read real quotes from published authors. 